\title{
Article \\ Older Adults' Experience of an Exergaming Intervention to Improve Balance and Prevent Falls: A Nested Explanatory Qualitative Study
}

\author{
Christine Rogers ${ }^{1, *}$, Delva Shamley ${ }^{2}$ and Seyi Amosun ${ }^{1}$ (i) \\ 1 Department of Health and Rehabilitation Sciences, Faculty of Health Sciences, University of Cape Town, \\ Cape Town 7925, South Africa; seyi.amosun@uct.ac.za \\ 2 Clinical Research Centre, Faculty of Health Sciences, University of Cape Town, Cape Town 7925, South Africa; \\ delva.shamley@uct.ac.za \\ * Correspondence: Christine.Rogers@uct.ac.za; Tel.: +27-21-406-6315; Fax: +27-0866110725
}

Citation: Rogers, C.; Shamley, D.; Amosun, S. Older Adults' Experience of an Exergaming Intervention to Improve Balance and Prevent Falls: A Nested Explanatory Qualitative Study. Appl. Sci. 2021, 11, 11678. https://doi.org/10.3390/ app112411678

Academic Editor: Hanatsu Nagano

Received: 30 September 2021

Accepted: 29 November 2021

Published: 9 December 2021

Publisher's Note: MDPI stays neutral with regard to jurisdictional claims in published maps and institutional affiliations.

Copyright: (c) 2021 by the authors. Licensee MDPI, Basel, Switzerland. This article is an open access article distributed under the terms and conditions of the Creative Commons Attribution (CC BY) license (https:/ / creativecommons.org/licenses/by/ $4.0 /)$.

\begin{abstract}
Falls are frequent and life-changing events for older adults worldwide. The ageing phenomenon has arrived in developing countries, which experience tensions between curative and rehabilitative services, combined with an increase in non-communicable diseases. Policies addressing issues of ageing have been poorly implemented, and there are few fall prevention initiatives. Compelling evidence from the Global North supports exercise-based interventions to improve balance and reduce fall risk in older adults. More recently, attention has focused on interactive videogaming, known as exergames, as a novel way to manage fall risk with exercise. Commercially available exergames have inherent appeal for low- and middle-income country contexts, where rehabilitation professionals and resources are scanty. The aim of this study was to explore the feasibility of a large-scale randomized control trial comparing an exergaming intervention with the gold-standard Otago Exercise Programme and a no-intervention arm. Exercise adherence was poor in both intervention arms, and this prompted a shift to mixed methodology to explore the construct of falls and participants' experience of the exergaming intervention. Focus groups were conducted, and the results were analysed using content analysis. Whereas the results demonstrated improvements in physical outcome measures (e.g., Timed-Up-and-Go, MiniBESTest) related to balance and falls that were encouraging in both the gold-standard and exergaming intervention groups, few participants achieved optimal adherence. Attitudes toward falls and fall prevention were explored, as well as participants' experiences of the exergaming programme. Consistent with a developing country context, participants acknowledged both intrinsic and extrinsic fall risk factors. Exergaming participants enjoyed the fun and playful aspects of the exercise programme, yet these were not sufficient to maximize adherence. The focus groups described the barriers and facilitators to participation, which included motivation. The focus groups discussed strategies to enhance participation, and these are discussed in the context of exergaming.
\end{abstract}

Keywords: falls; fall prevention; exergames; barriers; facilitators; adherence

\section{Introduction}

The world's population is ageing, and emerging regions will not be spared from this phenomenon. In sub-Saharan Africa, the population of older adults is predicted to double between 2000 and 2030. The notion of longevity and its equivalence with the success of humanity persists [1,2], and should indeed be celebrated [3]. However, such progress is remarkable only if living longer is associated with improved quality of life, health and wellbeing, which is not necessarily the case in Africa [1]. With the proliferation of both ageing and non-communicable diseases in South Africa, the nation faces numerous challenges [4]. First, while health care system reform has achieved some success, inequitable conditions prevail [5]. Older adults report difficulty accessing services [6], and perceive the quality of 
health care provided as poor and uncaring [7]. In many developing countries, rehabilitation, often required for the management of chronic diseases, is still regarded as a putative luxury [8], and is often unavailable or under-resourced. Second, poor socioeconomic status and sociodemographic factors remain negatively associated with the burden of disease [9], leaving a disempowered, underserved population vulnerable to ill health, including falls.

Decades ago, falls were described as one of the 'geriatric giants' of ageing [10]. The status for falls is unchanged in the 21st century, but with markedly disproportionate increases in mortality and morbidity data. In addition, falls are a significant public health concern due to their associated costs [11-13]. Globally, almost one in three adults (29\%) over 65 years old will fall each year [14]. Few studies have described the fall risk factors or prevalence of falls in South Africa, the setting for this study. However, one small study of community-dwelling adults over the age of 40 years supports the notion that the prevalence is similar to developed countries [15].

Compelling evidence supports the use of exercise-based fall prevention programmes, which can significantly reduce the risk of falls for older adults [16]. One of the most successful is the Otago Exercise Programme (OEP) [17-19]. The OEP is an individualized, home-based programme usually supported by a health care professional such as a physiotherapist. Whereas the OEP is well founded in evidence and has been proven to be cost-effective [20], the suitability for such a programme in South Africa is questionable due to the disarray in the health care section already described, along with a critical shortage of skilled human resources [21]. Recently, research has focused on technology-based interventions and their potential to reduce fall risk in older adults. Options have included video classes of programmes such as the OEP [22], true virtual reality or home-based virtual reality programmes [23-25] and commercially available interactive videogaming programmes, known as exergaming [26]. The Wii Fit Balance Board (WBB) is an example of the latter.

Given the resource constraints in African countries, who are largely failing to implement policies to manage a pandemic of age-related issues [27] including falls, systems like the WBB are appealing as prevention and rehabilitation tools. Equipment is relatively inexpensive and suitable for use in a domestic setting. Internet access is not required as the WBB operates from a television. Little would be required in terms of resources, highly trained staff and supervision, making fall prevention programmes possible in poorly served and even rural settings.

The aim of the study was to conduct a feasibility cluster-randomized control trial examining the implementation of a WBB exercise programme against a usual care arm, along with a group of participants who underwent the OEP, held as the gold standard. The feasibility objectives included the evaluation of the suitability of sites to accommodate a large-scale trial, costs for a future trial, the refinement of eligibility criteria, sample size estimation, adherence, attrition and safety monitoring. Feasibility objectives do not place a heavy emphasis on efficacy data, as sample sizes are generally small [28]. However, physical outcome measures related to balance and fall risk, including the Timed-Up-and-Go (TUG) test, Dynamic Gait Index (DGI) and MiniBESTest, were conducted at trial entry and 3- and 6-month follow-up visits, along with self-assessment scales related to quality of life (EQ-5D-3L), the Self-Efficacy for Exercise (SEE) scale and the Physical Activity Scale for the Elderly (PASE). During the clinical trial, it emerged that participants were not very adherent to the programme despite regular follow-up and diarizing exercise sessions. The reasons offered for poor adherence during informal feedback with the lead researcher included being short of time, frightened of the technology and the emergence of health conditions that prohibited or reduced the participant's ability to exercise. A desire to understand the motivations for adherence or withdrawal from the WBB arm of the study prompted a shift in methodology to a mixed methods paradigm. An explanatory qualitative study [29] was nested within the trial. Focus groups explored participants' constructs of falls and their experiences of the exergaming intervention. The qualitative results are presented here. 


\section{Materials and Methods}

The aim of the qualitative aspect of the study was to explore participants' constructs of falls and fall prevention. In addition, participants were invited to share their experiences, including barriers and facilitators regarding adherence, with the WBB exergaming intervention.

\subsection{Framework for the Focus Group Design}

The design employed an explanatory qualitative design [29] using focus group interviews, and subsequent qualitative and quantitative content analysis [30]. The study design is described further in the Section 3. Specifically, an individualistic social psychology lens was used, which is a common approach to explore patient satisfaction or the effects of programmes [31].

\subsubsection{Sampling Strategy and Size}

The sampling frame was all 14 OEP and 16 WBB participants who commenced the intervention in the overarching study. Adherence was not a selection criterion, as reasons for adherence or attrition were of interest. From this frame, a convenience sample of participants willing to enrol in the qualitative study was drawn [32]. All participants attending follow-up at 6 months were invited to join a focus group irrespective of their adherence patterns. The relatively homogenous nature of participants in terms of socioeconomic status and other common features assisted with the focus, simplification and smoothing of group dynamics [33]. The overall sample size was fifteen older adults, two of whom were male. Two focus groups (six and five participants, respectively) were held for the WBB participants, and one focus group was held for the four participants from the OEP group. It is acknowledged that the ideal size for focus groups is between six and eight participants. However, more participants and groups do not necessarily contribute to richer data [34], and in this instance, the authors felt that data saturation had been achieved. More details are provided in the Study Setting section.

\subsubsection{Study Participants and Setting}

Two of the four sites enrolled in the trial were randomized to the WBB. The cluster design of the overarching study ensured participants at each site were only offered one of the interventions and were unaware of which was the experimental intervention (WBB). All sites were residential communities of retirement apartments for independent older adults located in middle- to upper-income suburbs in Cape Town, South Africa. Neither of the WBB sites had on-site catering or nursing facilities. Participants' ages ranged from 65 to 91 years. All participants had a minimum of secondary (high school) education, and all but one was mother-tongue English speaking. Groups were held in private, comfortably furnished common rooms at each site.

To enter the main study, participants had to have either fallen in the year preceding enrolment or be at fall risk, established by case history and validated physical outcome measures (e.g., TUG, MiniBESTest, preferred walking speed). As one of the aims of the feasibility study was to refine the eligibility criteria, the initial inclusion and exclusion criteria were kept as non-restrictive as possible. Participants had to be ambulant, have use of their hands/arms to facilitate game play and not screen positive for risk of cognitive impairment (established using the Mini-Cog) or depression (Geriatric Depression Scale), as both conditions might impact participation in an exercise programme. The intended dose of WBB and its accompanying walking programme was a minimum of 2 hours per week, in line with best practice guidelines [35], for 6 months. None of the participants achieved this target, confirming sub-optimal adherence and signalling the need to explore the reasons for such data. 


\subsection{Procedure}

\subsubsection{Permissions and Consent}

The study was designed in accordance with the principles in the Declaration of Helsinki (2013 version). The researcher endorses the Singapore Statement on Research Integrity [36]. Ethical clearance was granted by the University of Cape Town Faculty of Health Sciences Human Research Ethics Committee (HREC reference number 818/2015; focus group amendment 1.11.2017), and the trial was registered with the appropriate bodies (PACTR 20160300151 3802). Consent procedures specific to focus groups were implemented, including outlining the limitations to confidentiality.

\subsubsection{Focus Group Discussions}

Refreshments were served and a relaxed, informal atmosphere was created. To avoid any potential awkwardness should the participants have wished to discuss anything they would prefer not to say directly to the researcher, a trained facilitator managed the groups. A topic guide was used to initiate the discussion (see Appendix A). Audio recording captured the conversation. Overall, the discussions lasted 90 minutes.

\section{Data Analysis}

A qualitative content-orientated analysis [31] was used, a process described as a method in its own right [30]. Content analysis yields an unambiguous description of the content of the group conversation that comprises a focus group, although there is less consideration and probing of implied meanings [37]. A descriptive approach was adopted, with qualitative data showing what has been said, and quantitative information highlighted the frequency of the codes counted [37]. The latter quasi-statistical data may provide more meaning regarding the level of agreement on the issues discussed [38].

\subsection{Phases in the Analysis Process \\ 3.1.1. Preparatory Phase}

Verbatim transcripts were prepared and read several times to familiarize the researcher and provide an overall sense of the data. As the discussions were straightforward, transcripts were managed using a standard word processing package, and specialized software (e.g., NVivo) was unnecessary.

\subsubsection{Organizing Phase}

Meaning units of text were condensed and then coded into categories, which are the main product of the analytical process. Then, these categories contribute to the development of themes [37]. In content analysis, themes may be influenced by the frequency of categories occurring in the text [39].

\subsubsection{Reporting Phase}

The reporting phase is the final stage of data analysis. A quantitative count of categories and sub-categories was completed [40]. Key pieces of text were selected to illustrate themes and assist with answering the research question.

\section{Trustworthiness}

Specific to content analysis methodology, inter-coder reliability (akin to inter-rater reliability in quantitative research) is recognized as a way to improve trustworthiness [41]. Checking for coding consistency at two points in time supports quality assurance. A sample of data was initially coded. Then, coding was repeated 10 days later to evaluate and modify the coding frame [30]. Triangulation was achieved using different methods for data collection, in this case adherence data. Concept-driven validity was tested by comparing the results with what is already known to experts in the research topic [30]. As marked attrition and participant fatigue impacted the study, member checking was not done to avoid further burdening the participants. However, the resulting analysis 
was reviewed by the facilitator, who agreed that the essence of the discussion had been captured appropriately. Although there was a small sample size, the concepts discussed were clearly delineated and similar between groups. Therefore, it is likely data saturation was achieved.

\section{Results}

5.1. Participants' (OEP and WBB) Attitudes towards Falls and Fall Prevention

Figure 1 demonstrates the process of assigning a theme for the construct of falls.

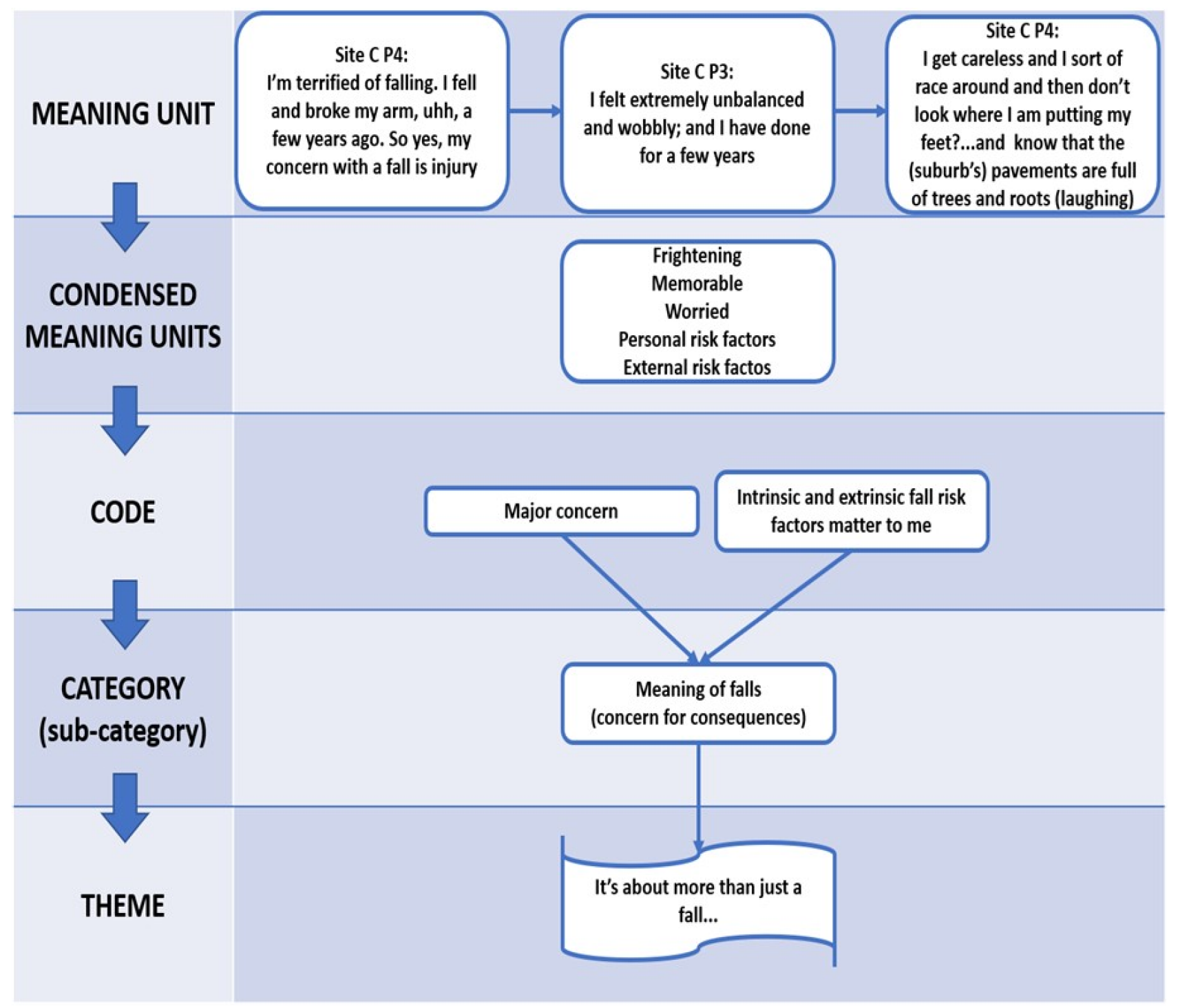

Figure 1. The process constructing meaning units leading to codes and themes.

Theme: It's about more than just a fall ...

The key issues based on their frequency during discussion were:

Fear of falling (19 mentions), and previous injurious falls (14 occurrences), which subsequently enhanced the fear of falling. Site C participant P1's opinion that (No participant elected to assume a pseudonym. Due to the mixed methods design, assigning participants P1, P2 etc., was considered acceptable): "I think it's the incapacity ... the injury and all that, that's why you're scared," demonstrates a strong association between the fear of falling and injurious falls. Consequences of falls were discussed with reference to a potential loss of independence, a serious concern voiced across all groups. 
Site B P6's statement reflects both groups' overall discussion:

"I must say that the pain, the pain of it ( fall) (doesn't bother me at all. (But) the fear of a broken bone, and the long-term effects of it, which could, depending on how old you are, last for the rest of your life. That's what really concerns me. It might send me over to Site A (reference to neighbouring facility with frail care facilities)! Because of a broken bone, and I am no longer able to look after myself. ... It's all the long-term effects that concern me." (Note: items in italics and parenthesised are insertions/changes by the lead researcher to aid with context or grammatical issues).

Site B P1 echoed with: "It ( $\mathrm{fall}$ ) takes a second, it takes a minute, and you live with it for several weeks." Site B P5 added: "I think I am very independent (and), the thought of having to be dependent on people just freaks me out totally!"

Figure 2 shows words used by participants to describe their construct of falls and their consequences. In the word cloud (constructed with MS Word), the larger words were mentioned most frequently.

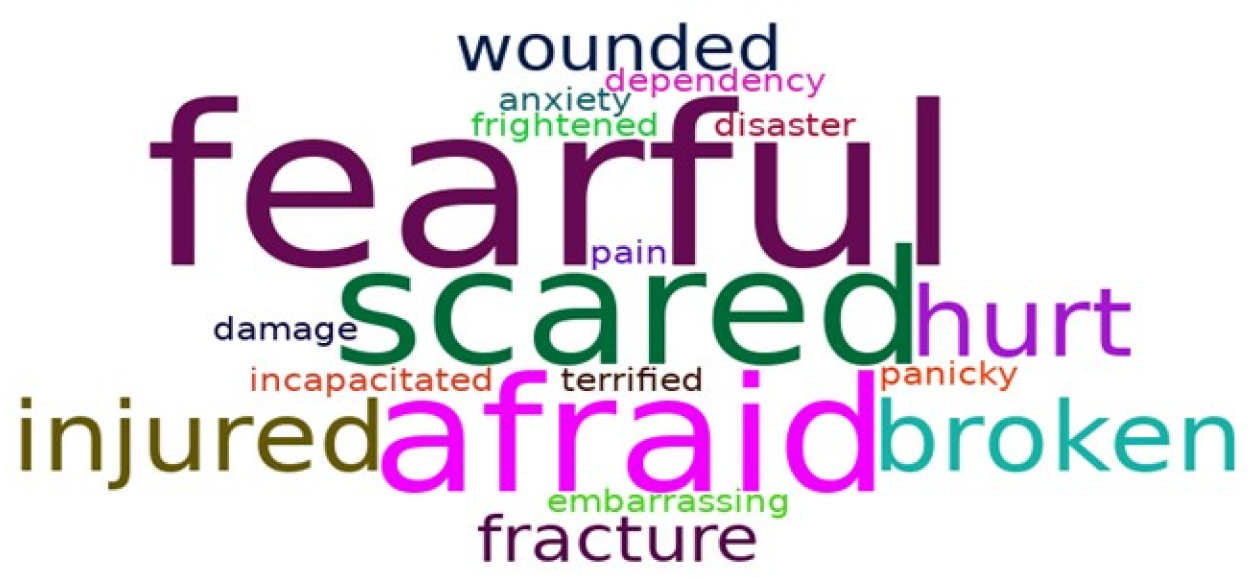

Figure 2. Word cloud depicting participants' description of the consequences of falls.

Recognition of intrinsic risk factors contributing to falls (19 mentions). Participants showed some insight into intrinsic fall risks and management strategies developed during the intervention. Site C P3 described risk management:

"Well, I have to tell you, well yes, I do now (implement fall prevention strategies) because I've been made aware (by the intervention). I've also been made aware of my feet. What's happening to my feet. ... I umm, probably shouldn't say the next thing, but I am. The last few weeks almost, I can't tell you what a big change it's (WBB) made in my life! And my family noticed that! (Facilitator uses a continuer to encourage more detail). They say I am walking better! (Before the intervention) I think I must have slowed down; and was looking at my feet and going on oddly."

Participants cited lack of concentration or confidence, inability to dual-task, and carelessness contributing to fall events. Site B P2 noted: "I can trip over fresh air!". Ageing was mentioned as a contributor to falls, particularly feeling younger than one's chronological age and not being mindful of fall risks. Site B P2 quipped: "Just believing that I'm 35 (years old) instead of a lot more!" (Laughter in the room).

\subsection{WBB Participants' Experience of the Intervention}

\section{Theme: acceptance and commitment}

The theme of acceptance and commitment was developed. Acceptance commenced with realization of the need for an intervention to improve balance. Both groups voiced sentiments of acceptance of being "older and wonkier" (Site C P1). The category of I am not as I was shaped the notion of acceptance of change, and that this change was not necessarily positive. The same participant had been considering self-help strategies to manage her fear of falling and arrived with high hopes: 
“I just thought it was going to be absolutely fantastic! I've been concerned about falling for a long time. And I have seen stuff on TV about doing things to help yourself. And that's why I (actually) came along, I thought it was going to be good!" (Site C P1).

Participants discussed factors enhancing commitment to the intervention. The participants also discussed the realization that WBB promoted the awareness of balance perturbations and improved reaction times and, thus, improved balance was evident. Site C P3 commented:

"Umm, just realising how our reaction times vary, whether you're falling backwards, falling forwards, falling sideways (body awareness created by WBB).... We are more aware of our posture, of our body, and what we are doing at the time."

Commitment was likely enhanced by a sense of mastery over balance-related tasks when playing exergames. Participants discussed specific games related to balance demands. Games levels had increasing balance challenges, which were met. The following exchange, where real-life benefits of the programme are described, is telling:

Site C P1: "So you're not hanging onto any support?"

Site C P4: "I'm not hanging onto stuff."

Group: "Oh, wow."

Commitment and motivation can be argued to be symbiotic. Motivation was a recurring category (26 condensed meaning units). Commitment wavered in WBB groups. Site B P2 (who was poorly adherent) mentioned:

"Umm, I enjoyed it! I found the difficult bit was making up my mind to do it! Once you've started, you carry on, but I think my balance improved a little bit."

Similarly, Site B P4 added that she became annoyed with herself for not continuing with the intervention, especially as she was improving. Participants mentioned waning interest over time. Site C P3 summed succinctly:

"Umm, I stayed because it was fun! I ran out of steam at the end. I almost felt I needed motivating again. I was like: 'come on now, rally yourself again.' Umm, (that was), I sort of got slap in the end." (The term 'slap' is an Afrikaans word meaning limp. The term is used commonly as slang to describe flaccid, over-cooked, limp potato chips (French fries), which are popular in the Western Cape. (Reference: accessed on 8 January 2019 from https:/ / theculturetrip.com/africa/south-africa/articles/18-south-african-slang-w ords-and-phrases-you-should-know/).

Participants frequently described themselves as lacking in 'discipline' (15 mentions). Site B P1, whose adherence was very poor, noted:

"I went through the course with a permanent guilty conscience. You know, I never improved with the balance exercises on the TV, on the video (WBB). I just never improved, and I really did try. I don't think I gave it my best shot because mainly, I didn't have the discipline, and I didn't have anyone to answer to."

Site B P4 agreed by noting her "laziness" and lack of self-discipline. At the same time, the importance of self-discipline was acknowledged by Site C P3: "I think there's no benefit without the discipline."

Despite the poor adherence of many participants, some positive aspects related to motivation. Particularly for Site B, the intervention promoted renewed interest in other forms of exercise and most continued with the walking programme (which supplemented the WBB intervention). P3 walked and added aqua aerobics and Pilates to her training regimen. P6 continues to walk at 91 years old. P4 perceived improvements, which then facilitated group exercise, which she found more enjoyable, and started line-dancing and yoga classes.

The barriers to the WBB are described next, but in this context, self-efficacy warrants consideration. The mean Self-Efficacy for Exercise (SEE) [42] score for the WBB group at baseline was 7.36 (SD 1.81; the maximum possible score, meaning highest self-efficacy for exercise, is 9). Scores declined with time to 6.85 (SD 1.47) at 3 months and 6.24 (SD 1.74) at 6 months. The trend toward a steady decline in self-efficacy triangulates well with the qualitative findings. 


\subsection{Barriers and Facilitators to Participation in the WBB Intervention}

This section has not been given a theme. Instead, barriers and facilitators will be discussed in turn.

\subsection{Barriers}

Dislike and irritation in response to the coaching avatar was mentioned frequently (34 condensed meaning units) and strongly at one site. Participants mentioned methods for circumventing the coaching avatar and suggested warming up in their apartments and then doing the exergames in the common room (where the equipment was located) may have been preferable. The following passage from Site C P4 is typical of the discussion:

"What I didn't like ... is all the comments in-between. In my opinion, they can be cut out. 'Ahh hello, haven't seen you for seven days'; or 'you've been coming every day' ... That sort of rubbish gets me.... Just move with the actual exercise! ... That's the only thing I disliked about the programme.... Cut out all the blurb! That I found disturbing, it irritated me."

Site C P2 agreed:

“Umm, umm ja (Afrikaans for 'yes', frequently used in South African colloquial English.) I think that, that guy (avatar), he needs to keep quiet, I think." (Laughter from the other participants).

Co-facilitator: "Don't you have a mute button (laughing)?"

P2: "No, you don't for him!"

Waning interest and lack of active monitoring were cited as barriers to participation. However, some participants acknowledged that the exercise log/calendar on which sessions were to be recorded by placing stickers for walks, WBB sessions and falls was motivating, as the following passage demonstrates:

Site C P3: "I loved it! I thought it was fun! I hadn't done those sorts of exercises for years. ... Umm, I got, ahh, slack at the end (clears throat). Almost, I felt somebody needed to galvanise me and say, 'where's your sticker?' ... I'm just a lazy person, I think! But I loved it, it was fun!"

Site C P4: “ . . I thoroughly enjoyed it! ... And yes, I do still do it, but not as regularly as was required in the beginning. Perhaps also because there's not someone sort of saying, 'have you done your exercises?' You know, (scoffs) almost like a school programme, where you need an exam at the end of two weeks (laughing)? Saying 'how far have you got, and what have you done?'. And that's where your follow up programme came in so well; because it makes you so aware and think-'I must get back to it!' You know! So yes, I still do it, but not as regularly as I should."

\subsection{Facilitators}

The challenge of exergaming facilitated play and increased practice. Site C P4 noted:

"I liked the challenge of trying to beat myself on those programmes! You know ... some days you can hit the soccer ball, and other days he (interactive avatar) sits and weeps on the grass (laughter)! ... I enjoyed that! I enjoyed the challenge of got to do better, got to do better!"

A sense of competition was enjoyable. Games such as skiing and those with scoring encouraged participation. Site C P2 commented:

"Well, I stayed because I just felt like I was getting somewhere! Except my scores weren't getting any better on those games! Yoh! Some days I'd say yoh, I'm gonna get 300 and I'd get 120. And the next day I'd get 80. And I thought 'no, this is crazy!', but I think it's the process that's more important that the scores."

It's a Wii bit of playful fun! Participants appreciated the imaginative aspects of WBB and the sense of playfulness. The benefits of participation were linked to a notion already discussed in terms of fall risk management, enhanced mindfulness of balance and balance challenges. Site C P2 continued: 
"And I enjoyed the ramping, uhm, the going down the ramp and seeing how far I could. $J a$, I was certain I was going to end up right on, in amongst the crowd! ... but anyway, $j a$, I think it's the whole process that's good. Because it makes you (because you're) aware of what's on, going on around you.'

Interactive nature of games was at times helpful. Although interaction with the avatar was discussed as a barrier to participation, the usefulness of the feedback was acknowledged. Site C P3 noted:

"With that guy (avatar) and he would say, 'your legs are shaking.' I think-I will smack you now (laughing)! Stop that! That's why I am here! My legs are shaking."

\subsection{Results of Systems Usability Scale}

The Systems Usability Scale (SUS) [43] is commonly used when researching individuals' experience with technology. It is reliable and valid, and resistant to slight changes in wording [44], which were made in this case by substituting the word 'product' with 'exergaming'. The scale scores range from $0-100$, with high scores suggesting more usability. Figure 3 provides examples of the WBB participants' experiences with the exergaming programme. Overall, SUS percentage scores indicated that equal numbers of respondents found the usability of the intervention to be either excellent or good (36\% of respondents each $=72 \%)$, while the remaining found the usability to be OK $(14 \%)$ or poor $(14 \%)$. Although the SUS suggested that the majority of participants found the WBB user-friendly and would use it again, the adherence data did not support this finding.

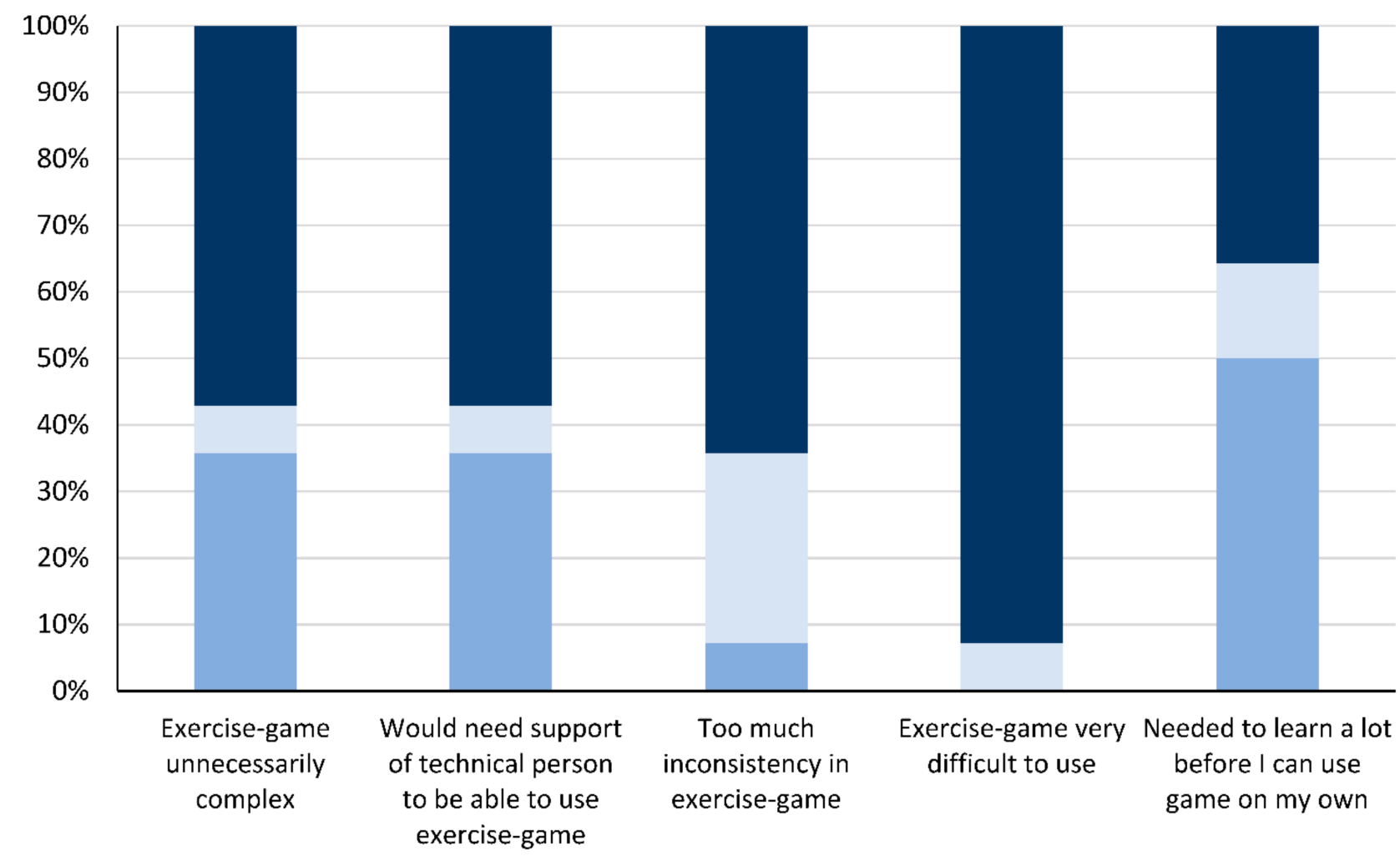

Strongly agree/Agree $\square$ Neutral $\square$ Strongly disagree/Disagree

Figure 3. WBB participants' Systems Usability Scale results.

\section{Discussion}

By $2050,80 \%$ of the world's older adults will reside in low- and middle-income countries [45]. However, adding to the sum of years lived does not imply years lived well. The number of older adults requiring either rehabilitation or long-term care will quadruple by 2050 due to the age-related loss of functional independence [45]. Pertinent 
to falls, a large multi-national study using walking speed as a proxy for function described firm associations between poor socioeconomic status and reduced physical function [46]. With many South Africans experiencing adverse social determinants of health in early life, along with a paucity of research concerning older adults and health on the continent $[47,48]$, the narrative concerning the need for care in the latter years is likely no different. Combined, socioeconomic issues clearly impact successful ageing and herald increasingly pressing demands from an ageing South Africa. Efforts aimed at fall risk identification and fall prevention are virtually non-existent in the region. Moreover, to avoid a major drain on scarce resources, novel management strategies, such as the use of exergaming for improving balance, should be explored with some urgency.

\subsection{Participants' Constructs of Falls}

Participants demonstrated awareness of several key notions concerning falls, namely intrinsic fall risks, including deterioration in balance and the appreciation of extrinsic fall risk. The results from this study have correlations with other qualitative work. Gardiner et al.'s (2017) narrative synthesis of qualitative research considering falls and fall risk highlighted older adults' dualistic thinking regarding fall risk. Acknowledgement of fall risk signified the acceptance of old age and possible infirmity [49], concepts identified in the "I am not as I was" category described in the Results section. Gardiner and colleagues (2017) cautioned that an unwillingness to accept fall risk and ageing could underpin the rejection of fall management efforts. Although the focus group participants suggested that their awareness of responses to balance perturbations had improved, they did not perceive these improvements as motivating enough to continue with the exercise programme. This finding is interesting considering that improvements in the exercise intervention groups approached Minimum Clinically Important Differences on physical endpoints such as the MiniBESTest and preferred walking speed. Moreover, there was a marked decline in fall occurrence (30\% reduction) in the WBB group, signalling an impressive improvement.

Researchers have reported older adults avoiding hazards using strategies such as caution/carefulness and reflection before action $[49,50]$. Participants in the current study noted environmental challenges and a realization that these presented a risk for falls. Poor infrastructure in emerging regions, such as potholes, absent or uneven pavements and home hazards, including lack of indoor bathrooms, have all been shown to represent fall risk $[51,52]$. In a developing country like South Africa, attention to such risks in the built environment would be beneficial. Raising awareness of how older adults interact with their physical surroundings would only be helpful. However, excessive carefulness might promote the avoidance and fear of falling [49], as discussed next.

The groups explored the fear of falling at some length. Fear of falling is a prevalent condition in older adults resulting in reduced activity levels, the loss of autonomy and social isolation [53]. Participants feared restricted independence and lasting negative sequelae of falls. Payette and colleagues (2016) convincingly argued for the links between fear of falling and generalized anxiety disorder. Interestingly, $45 \%$ of the participants in the overarching South African study were using prescribed psychotropic medications. Whereas post-fall syndrome and its associated health issues are multi-factorial in nature [54], a background of depression and anxiety sufficient to trigger prescription medication was notable in the South African participants. Indeed, psychotropic medication has been associated with increased fall events [55], leading to calls to manage such drugs in older adults by de-prescription and other methods [56]. Moreover, under-appreciation of the psychological factors capable of influencing participants' adherence to exercise was likely in play. Although not an endpoint of the current study, certain authors have examined the positive impact of exercise on depression [57] and anxiety [58]. Future appropriately powered randomized control trials examining exercise-based intervention to improve 
balance and prevent falls should consider the ability of exercise to reduce the reliance on medication for mood.

\subsection{Participants' Experiences with the WBB Intervention}

Prior to discussing facilitators and barriers to participation, adherence will be explored briefly. Adherence to exercise recommendations has been described as a participant's bond to an exercise programme [59]. Overall, adherence to exercise recommendations is extremely variable [60], and resistance to exercise common [61]. Specifically, adherence and attrition in fall prevention exercise programmes is extremely problematic [62]. Relevant to this report, where the participants had either fallen in the preceding year or been evaluated as at fall risk, evidence suggests that individuals with previous falls are reluctant to challenge balance in exercise $[63,64]$.

Low levels of adherence were evident. The target for exercise (WBB and walking programme) was set at 2 hours per week or $50 \mathrm{~h}$ over 6 months, as suggested by best practice guidelines [65]. Data were too few for computation at the 6-month point, but at 3 months, only $31 \%$ of the 16 WBB participants were meeting a 2 hour per week target. Although interventions were initiated and supervised regularly by a physiotherapist, they were home programmes, which are known to be associated with poor adherence [64].

\subsection{Motivation Challenges and Possible Solutions \\ 6.3.1. Shift to Group Activity}

The focus groups described a lack of motivation, and classes (OEP intervention) and teams playing exergames were suggested as solutions. Participants noted that group activities would oblige them to "be responsible" and "not let others down", hinting at potentially powerful motivators for adherence. Peer-led and group OEP classes have been successful in populations with fall risk, with psychological and social benefits reported [66]. Specifically, peer leaders are effective in promoting adherence to exercise [67], including in older adult populations [68]. Classes or team activities may offer practical and logistic advantages while enhancing adherence and possibly benefits. Moreover, the social aspects of group exercise are important in older adults [69]. Playing exergames in teams could well enhance immersion, increase fun and improve confidence [70]. Certainly, in a resourceconstrained setting, the group application of interventions, led by lay individuals, would be more cost-effective than individualized programmes.

\subsubsection{A Wii Bit More Fun}

Wu and colleagues [71] logically proposed that enjoyment of exergaming would make it preferable to conventional exercise, which is often repetitive and boring. Unexpectedly, the authors found the opposite, suggesting that exergaming might be difficult for older adults with little experience of interactive gaming [71]. Further, previous failure at managing interactive games could be demotivating. Previous challenges and a lack of customization of exergames for older adults might result in poorer adherence [71]. Humour and mentoring, as described in the study by Zhang et al. (2016), in which peer-coaching for WBB bowling tournaments was favourably received, might overcome such obstacles [70]. Team/group classes are suitable for sites similar to those in this trial, which had common areas for games to take place and other participants close by. The researcher was struck by the sense of community at the sites, which could be advantageous if changing the nature of intervention delivery. As evidence to support the use of exergaming mounts, and improvements in balance and mobility are proven by meta-analyses, future randomized control trials should be stringently designed [72].

Although adherence was challenging, attrition in the WBB group was reasonable compared with the literature. A meta-analysis of exercise-based interventions for falls cited attrition as ranging from 7.4 to $32.2 \%$ [73]. Focusing on WBB, Larsen and colleagues cited similar rates varying from 0 to $33 \%$ attrition [74]. Naturally, reasons for attrition vary. A relatively recent large (1016 participants) Spanish study of WBB for fall prevention showed 
that over one in three participants had withdrawn by 3 months, reaching almost half $(46 \%)$ at trial termination [75]. Attrition in the current study was relatively modest at $18.8 \%$ for the WBB groups at 6 months. One possible explanation is the desire of participants to maintain goodwill toward the researcher.

\subsubsection{Use of Methods to Enhance Self-Efficacy: Motivational Interviewing}

Along with not wishing to exercise alone, a common reason for not doing so [76], focus groups mentioned poor motivation as a barrier to participation. Lack of motivation and poor health (suggested by the number of comorbidities and medications present in the sample) are frequently cited reasons to not adopt optimal physical activity levels [77]. Motivational interviewing uses a variety of person-centred tools to promote and support behavioural change [76]. Motivational interviewing is emerging in the audiology literature as a tool to encourage individuals to adopt and use amplification [78]. However, the technique is seldom used in physiotherapy or fall prevention programmes [79]. Future clinical trials should explore techniques to enhance adherence and reduce attrition.

\section{Conclusions: Lessons Learned and Future Directions}

The feasibility cluster-randomized control trial and its qualitative component produced several useful findings. Attitudes toward falls and the fear of falling are similar to that reported in the global literature but have not been reported in South African participants to date. Given the diverse linguistic and cultural groups, future work should explore falls and related constructs in different settings to establish the need and awareness of fall interventions. For instance, it is not known if falls are a taboo subject in certain ethnic groups. Moreover, the health and societal consequences of falls are likely to be no different in an ageing population in an emerging region. Whereas Afro-centric communities have a tradition of family responsibility and intergenerational care [80] similar to that of filial piety in Asia [81], scholars are questioning the erosion of such values, meaning that state resources will have to be provided to care for older adults [80]. Thus, efforts aimed at fall prevention should be prioritized. This feasibility study is a first step toward larger-scale studies and, eventually, programme implementation.

Balancing adherence and attrition is important, and this study showed that while intervention participants availed themselves for follow-up assessments, allowing the collection of quantitative data to support preliminary evaluations of improvements in balance and possible reduction of fall risk, their exercise dose was sub-optimal. Low levels of adherence have been reported for both randomized control trials and fall prevention programmes. From a developing country perspective, sub-optimal participation is especially concerning where research funding is limited, and researchers have an ethical imperative to ensure their work is relevant to the population they serve rather than burdensome. Having older adults and their communities involved in every stage of the research design might alert researchers to potential issues which could impact the results of a fully powered study. Finally, maintaining the 'personal touch' could have underpinned the lack of attrition, but not supported adherence, so realizing older adults' appreciation of participant-centred contact is an important lesson for success in future trials.

The WBB intervention was designed and implemented by physiotherapists, and participants articulated the benefit to balance (upheld by physical endpoints such as improvements in TUG scores, preferred walking speed and MiniBESTest). Whereas the SUS suggested that participants had mastered the technology of the WBB and found it userfriendly, the exergaming avatar produced irritation. Negative affective responses might have reduced enthusiasm to engage with the intervention, an impact which would appear to be contrary to one of the 'selling points' of exergaming, that is, fun and immersion. Briefer warm-up periods and more explanation of the improvements and their meaning for falls could be built into future programmes.

Although participants noted that the completion of a calendar on which exercise sessions, walks and falls were recorded was, at times, motivating, it also induced feelings 
of guilt when participants did not do so regularly. Both the OEP and WBB interventions had monthly follow-up (either a phone call or personal visit by the physiotherapist). However, more regular follow-up could have enhanced motivation. A possible solution could be to consider an app-based reminder and feedback system. Most $(\approx 80 \%)$ South Africans have access to smartphones [82], although research suggests that older adults prefer to use the devices for calls or texts rather than accessing apps [83]. Moreover, owning a mobile phone does not necessarily imply competence with it [84], so the interface would have to be user-friendly and uncluttered. With the proliferation of telehealth partially spurred by the current pandemic, advances in tailoring programmes for older adults can be expected. Furthermore, adapting the WBB to allow logging of more participants and their sessions might allow for more reliable tracking of exergaming sessions. Advances in smart phone technology allow both walks and falls to be monitored and reported, holding promise for accurate and easy tracking. The results from this study showed that the participants, many of whom had little or no computer literacy, could embrace exergaming interventions, at least initially. The challenge will be to keep the bond of exercise adherence.

Author Contributions: Conceptualization, C.R.; Formal analysis, C.R.; Methodology, C.R.; Supervision, D.S. and S.A.; Writing - original draft, C.R. All authors have read and agreed to the published version of the manuscript.

Funding: This research was funded by the National Research Foundation of South Africa (Grant Number: 110802) and the Harry Crossley Fellowship, 2017, University of Cape Town.

Institutional Review Board Statement: The study was conducted according to the guidelines of the Declaration of Helsinki (2013 version), and approved by the Human Research Ethics Committee of the Faculty of Health Sciences, University of Cape Town (protocol code HREC818/2015 and focus group amendment 1.11.2017)."

Informed Consent Statement: Informed consent was obtained from all participants involved in the study. Participants were re-consented prior to the focus groups.

Data Availability Statement: The data presented in this study are available on request from the corresponding author. The data are not publicly available due to privacy restrictions.

Conflicts of Interest: The authors declare no conflict of interest.

\section{Appendix A. Topic Guide}

Topic: Falls and fall management

What do you think might contribute to your risk of falling?

Do you know of any strategies to prevent or manage the risk of falling?

Topic: Trial intervention and adherence

Sample questions adapted from Wollesheim, Merkes, Shields, Liamputtong, Wallis, Reynolds et al. [85]:

Why did you join the programme?

Why have you stayed or left the programme?

What was good about the intervention?

What was hard about the intervention?

Probes:

What did you like about it?

What did you dislike about it?

What would you change?

Would you do it again/recommend it/like this to be provided permanently for you? 


\section{References}

1. Da Silva Francisco, A.A. 'Gerontogrowth' and population ageing in Africa and the Global AgeWatch Index. J. Econ. Ageing 2017, 9, 78-89. [CrossRef]

2. Hornby-Turner, Y.C.; Peel, N.M.; Hubbard, R.E. Health assets in older age: A systematic review. BMJ Open 2017, 7, 013226. [CrossRef]

3. Apt, N.A. Preface. In Ageing in Africa: Sociolinguistic and Anthropological Approaches; Makoni, S., Stroeken, K., Eds.; Routledge: London, UK, 2017; Available online: https:/ /books.google.co.za/books?hl=en\&lr=\&id=QTg7DwAAQBAJ\&oi=fnd\&pg=PT7\&d $\mathrm{q}=$ Africa $+\% 2 \mathrm{~B}+$ ageing\&ots=PYIQMTMWgv\&sig=6Vkri6kIZrjJkU2tkJOWEN8na_Y\#v=onepage\&q=Africa $\% 20 \% 2 \mathrm{~B} \% 20 \mathrm{ageing}$ $\& \mathrm{f}=$ false (accessed on 2 May 2018).

4. Ajaero, C.K.; De Wet, N.; Odimegwu, C.O. Integrating rural-urban differentials in the appraisal of prevalence and risk factors of non-communicable diseases in South Africa. GeoJournal 2020, 85, 1-15. [CrossRef]

5. Burger, R.; Christian, C. Access to health care in post-apartheid South Africa: Availability, affordability, acceptability. Health Econ. Policy Law 2020, 15, 43-55. [CrossRef]

6. Lewitte, K.; Singh, A. Aging in South Africa. In Functional Performance in Older Adults, 4th ed.; Bonder, B.R., Dal Bello-Haas, V., Eds.; FA Davis: Philadelphia, PA, USA, 2018; pp. 53-58.

7. Kelly, G.; Mrengqwa, L.; Geffen, L. “They don't care about us”: Older people's experiences of primary healthcare in Cape Town, South Africa. BMC Geriatr. 2019, 19, 98. [CrossRef]

8. Morris, L.D.; Grimmer, K.A.; Twizeyemariya, A.; Coetzee, M.; Leibbrandt, D.C.; Louw, Q.A. Health system challenges affecting rehabilitation services in South Africa. Disabil. Rehabil. 2021, 43, 877-883. [CrossRef]

9. Amoateng, A.Y.; Biney, E.; Ewemooje, O.S. Social determinants of chronic ill-health in contemporary South Africa: A social disadvantage approach. Soc. Sci. J. 2021, 58, 1-15. [CrossRef]

10. Isaacs, B. The Challenge of Geriatric Medicine; Oxford Medical Publications: Oxford, UK, 1992.

11. Gazibara, T.; Kurtagic, I.; Kisic-Tepavcevic, D.; Nurkovic, S.; Kovacevic, N.; Gazibara, T.; Pekmezovic, T. Falls, risk factors and fear of falling among persons older than 65 years of age. Psychogeriatrics 2017, 17, 215-223. [CrossRef] [PubMed]

12. Li, F.; Eckstrom, E.; Harmer, P.; Fitzgerald, K.; Voit, J.; Cameron, K.A. Exercise and fall prevention: Narrowing the research-topractice gap and enhancing integration of clinical and community practice. J. Am. Geriatr. Soc. 2016, 64, 425-431. [CrossRef]

13. Paul, S. Falls: Prevention and Management. In Geriatric Medicine. A Problem-Based Approach; Nair, B.K.R., Ed.; Springer: Singapore, 2018; pp. 109-119.

14. Ganz, D.A.; Latham, N.K. Prevention of falls in community-dwelling older adults. N. Engl. J. Med. 2020, 382, 734-743. [CrossRef] [PubMed]

15. Rogers, C. Measures of falls, static and dynamic balance in independent older adults in Cape Town, South Africa. J. Vestib. Res. 2016, 26, 201. [CrossRef]

16. Sherrington, C.; Fairhall, N.J.; Wallbank, G.K.; Tiedemann, A.; Michaleff, Z.A.; Howard, K.; Clemson, L.; Hopewell, S.; Lamb, S.E. Exercise for preventing falls in older people living in the community. Cochrane Database Syst. Rev. 2019. [CrossRef]

17. Albornos-Muñoz, L.; Moreno-Casbas, T.; Sánchez-Pablo, C.; Bays-Moneo, A.; Fernández-Domínguez, J.C.; Rich-Ruiz, M.; GeaSánchez, M. Efficacy of the Otago Exercise Programme to reduce falls in community-dwelling adults aged 65-80 years old when delivered as group or individual training. J. Adv. Nurs. 2018, 74, 1700-1711. [CrossRef]

18. Patel, N.N.; Pachpute, S. The effects of Otago Exercise Programme for fall prevention in elderly people. Int. J. Physiother. 2015, 2, 633-639. [CrossRef]

19. Thomas, S.; Mackintosh, S.; Halbert, J. Does the 'Otago exercise programme' reduce mortality and falls in older adults? A systematic review and meta-analysis. Age Ageing 2010, 39, 681-687. [CrossRef]

20. Deverall, E.; Kvizhinadze, G.; Pega, F.; Blakely, T.; Wilson, N. Exercise programmes to prevent falls among older adults: Modelling health gain, cost-utility and equity impacts. Inj. Prev. 2019, 25, 258-263. [CrossRef]

21. Rispel, L.C.; Blaauw, D.; Ditlopo, P.; White, J. Human resources for health and universal health coverage: Progress, complexities and contestations. South Afr. Health Rev. 2018, 2018, 13-21.

22. Benavent-Caballer, V.; Rosado-Calatayud, P.; Segura-Ortí, E.; Amer-Cuenca, J.J.; Lisón, J.F. The effectiveness of a video-supported group-based Otago exercise programme on physical performance in community-dwelling older adults: A preliminary study. Physiotherapy 2015, 102, 280-286. [CrossRef] [PubMed]

23. De Amorim, J.S.C.; Leite, R.C.; Brizola, R.; Yonamine, C.Y. Virtual reality therapy for rehabilitation of balance in the elderly: A systematic review and meta-analysis. Adv. Rheumatol. 2018, 58, 18. [CrossRef] [PubMed]

24. Mirelman, A.; Maidan, I.; Shiratzky, S.S.; Hausdorff, J.M. Virtual reality training as an intervention to reduce falls. In Falls and Cognition in Older Persons; Montero-Odasso, M., Camicioli, R., Eds.; Springer: Cham, Switzerland, 2020; pp. $309-321$.

25. De Oliveira, J.A.; Guaratto, T.F.; Bacha, J.M.R.; Evangelista, R.A.; Bocalini, D.S.; Greve, J.M.D.A.; Alonso, A.C. Virtual reality in the rehabilitation of the balance in the elderly. Man. Ther. Posturology Rehabil. J. 2018, 15, 481. [CrossRef]

26. Chao, Y.-Y.; Scherer, Y.K.; Montgomery, C.A. Effects of using Nintendo Wii (TM) exergames in older adults: A review of the literature. J. Aging Health 2015, 27, 379-402. [CrossRef] [PubMed] 
27. Saka, S.; Oosthuizen, F.; Nlooto, M. National Policies and older people's healthcare in Sub-Saharan Africa: A scoping review. Ann. Glob. Health 2019, 85, 1-7. [CrossRef]

28. Abbott, J.H. The distinction between randomized clinical trials (RCTs) and preliminary feasibility and pilot studies: What they are and are not. J. Orthop. Sports Phys. Ther. 2014, 44, 555-558. [CrossRef] [PubMed]

29. Cresswell, J.W.; Plano Clark, V.L. Choosing a mixed methods design. In Designing and conducting mixed methods research, 2nd ed.; Sage Publications: Thousand Oaks, CA, USA, 2011; pp. 53-106.

30. Schreier, M. Qualitative content analysis. In The Sage Handbook of Qualitative Data Analysis; Flick, U., Ed.; Sage: London, UK, 2014; pp. 170-183.

31. Ryan, K.E.; Gandha, T.; Culbertson, M.J.; Carlson, C. Focus group evidence: Implications for design and analysis. Am. J. Eval. 2014, 35, 328-345. [CrossRef]

32. Nagle, B.; Williams, N. Methodology Brief: Introduction to Focus Groups. Available online: http://www.mmgconnect.com/pro jects/userfiles/File/FocusGroupBrief.pdf (accessed on 29 April 2021).

33. Suzuki, L.A.; Ahluwalia, M.K.; Arora, A.K.; Mattis, J.S. The pond you fish in determines the fish you catch: Exploring strategies for qualitative data collection. Couns. Psychol. 2007, 35, 295-327. [CrossRef]

34. Fusch, P.I.; Ness, L.R. Are we there yet? Data saturation in qualitative research. Qual. Rep. 2015, 20, 1408-1416. [CrossRef]

35. Mora, J.C.; Valencia, W.M. Exercise and older adults. Clin. Geriatr. Med. 2018, 34, 145-162. [CrossRef] [PubMed]

36. Resnik, D.B.; Shamoo, A.E. The Singapore statement on research integrity. Account. Res. 2011, 18, 71-75. [CrossRef]

37. Vaismoradi, M.; Jones, J.; Turunen, H.; Snelgrove, S. Theme development in qualitative content analysis and thematic analysis. J. Nurs. Educ. Pract. 2016, 6, 100-110. [CrossRef]

38. Onwuegbuzie, A.J.; Dickinson, W.B.; Leech, N.L.; Zoran, A.G. A qualitative framework for collecting and analyzing data in focus group research. Int. J. Qual. Methods 2009, 8, 1-21. [CrossRef]

39. Vaismoradi, M.; Turunen, H.; Bondas, T. Content analysis and thematic analysis: Implications for conducting a qualitative descriptive study. Nurs. Health Sci. 2013, 15, 398-405. [CrossRef] [PubMed]

40. Bengtsson, M. How to plan and perform a qualitative study using content analysis. Nurs. Open 2016, 2, 8-14. [CrossRef]

41. O'Connor, C.; Joffe, H. Intercoder reliability in qualitative research: Debates and practical guidelines. Int. J. Qual. Methods 2020, 19, 1-13. [CrossRef]

42. Resnick, B.; Jenkins, L.S. Testing the reliability and validity of the self-efficacy for exercise scale. Nurs. Res. 2000, 49, 154-159. [CrossRef] [PubMed]

43. Brooke, J. SUS_A quick and dirty usability scale. In Usability Evaluation in Industry; Jordan, P.W., McClelland, B.T.I.L., Weerdmeester, B.A., Eds.; Taylor \& Francis: London, UK, 1996; pp. 189-194.

44. Lewis, J.R. The system usability scale: Past, present, and future. Int. J. Hum. Comput. Interact. 2018, 34, 577-590. [CrossRef]

45. Frontera, W.R. Physical activity and rehabilitation in elderly. In Rehabilitation Medicine for Elderly Patients; Masiero, S., Carraro, U., Eds.; Springer International Publishing: Cham, Switzerland, 2018; pp. 3-13.

46. Stringhini, S.; Carmeli, C.; Jokela, M.; Avendaño, M.; McCrory, C.; d’Errico, A.; Bochud, M.; Barros, H.; Costa, G.; ChadeauHyam, M. Socioeconomic status, non-communicable disease risk factors, and walking speed in older adults: Multi-cohort population based study. BMJ 2018, 360, k1046. [CrossRef]

47. Lloyd-Sherlock, P.; Amoakoh-Coleman, M. A critical review of intervention and policy effects on the health of older people in sub-Saharan Africa. Soc. Sci. Med. 2020, 250, 112887. [CrossRef]

48. Lloyd-Sherlock, P. Long-term care for older people in South Africa: The enduring legacies of apartheid and HIV/AIDS. J. Soc. Policy 2019, 48, 147-167. [CrossRef]

49. Gardiner, S.; Glogowska, M.; Stoddart, C.; Pendlebury, S.; Lasserson, D.; Jackson, D. Older people's experiences of falling and perceived risk of falls in the community: A narrative synthesis of qualitative research. Int. J. Older People Nurs. 2017, 12, 8. [CrossRef] [PubMed]

50. Tuvemo Johnson, S.; Martin, C.; Anens, E.; Johansson, A.-C.; Hellström, K. Older adults' opinions on fall prevention in relation to physical activity level. J. Appl. Gerontol. 2018, 37, 58-78. [CrossRef]

51. Amin, A.; Shawis, T.; Haines, R.; Merza, R.; Barawy, O. Falls in older people: A perspective from Kurdistan of Iraq. Middle East J. Age Ageing 2014, 11, 20-22. [CrossRef]

52. Worapanwisit, T.; Prabpai, S.; Rosenberg, E. Correlates of falls among community-dwelling elderly in Thailand. J. Aging Res. 2018, 2018, 10. [CrossRef]

53. Payette, M.-C.; Belanger, C.; Léveillé, V.; Grenier, S. Fall-related psychological concerns and anxiety among community-dwelling older adults: Systematic review and meta-analysis. PLoS ONE 2016, 11, e0152848. [CrossRef] [PubMed]

54. Lavedán, A.; Viladrosa, M.; Jürschik, P.; Botigué, T.; Nuín, C.; Masot, O.; Lavedán, R. Fear of falling in community-dwelling older adults: A cause of falls, a consequence, or both? PLoS ONE 2018, 13, e0194967. [CrossRef]

55. Seppala, L.J.; Wermelink, A.M.; de Vries, M.; Ploegmakers, K.J.; van de Glind, E.M.; Daams, J.G.; van der Velde, N.; Blain, H.; Bousquet, J.; Bucht, G. Fall-risk-increasing drugs: A systematic review and meta-analysis: II. Psychotropics. J. Am. Med Dir. Assoc. 2018, 19, 371.e11-371.e17. [CrossRef] [PubMed] 
56. Del Carmen Panini, A.; Teves, M.R.; Giraudo, E.; Garraza, M.H.; Calderón, C.P. Psychotropic medication use in the elderly. In Psychiatry and Neuroscience Update-Vol. II; Gargiulo, P., Mesones-Arroyo, H., Eds.; Springer: Cham, Switzerland, 2017 ; pp. 293-306.

57. Catalan-Matamoros, D.; Gomez-Conesa, A.; Stubbs, B.; Vancampfort, D. Exercise improves depressive symptoms in older adults: An umbrella review of systematic reviews and meta-analyses. Psychiatry Res. 2016, 244, 202-209. [CrossRef]

58. Stonerock, G.L.; Hoffman, B.M.; Smith, P.J.; Blumenthal, J.A. Exercise as treatment for anxiety: Systematic review and analysis. Ann. Behav. Med. 2015, 49, 542-556. [CrossRef]

59. Rivera-Torres, S.; Fahey, T.D.; Rivera, M.A. Adherence to exercise programs in older adults: Informative report. Gerontol. Geriatr. Med. 2019, 5, 1-10. [CrossRef] [PubMed]

60. Room, J.; Hannink, E.; Dawes, H.; Barker, K. What interventions are used to improve exercise adherence in older people and what behavioural techniques are they based on? A systematic review. BMJ Open 2017, 7, 019221. [CrossRef]

61. Pereles, L.; Jackson, R.; Rosenal, T.; Nixon, L. Listening with a narrative ear: Insights from a study of fall stories in older adults. Can. Fam. Physician 2017, 63, e50.

62. Osho, O.; Owoeye, O.; Armijo-Olivo, S. Adherence and attrition in fall prevention exercise programs for community-dwelling older adults: A systematic review and meta-analysis. J. Aging Phys. Act. 2018, 26, 304-326. [CrossRef]

63. Merom, D.; Pye, V.; Macniven, R.; van de Ploeg, H.; Milat, A.; Sherrington, C.; Lord, S.; Bauman, A. Prevalence and correlates of participation in fall prevention exercise/physical activity by older adults. Prev. Med. 2012, 55, 613-617. [CrossRef]

64. King, L.A.; Wilhelm, J.; Chen, Y.; Blehm, R.; Nutt, J.; Chen, Z.; Serdar, A.; Horak, F.B. Effects of group, individual, and home exercise in persons with Parkinson Disease: A randomized clinical trial. J. Neurol. Phys. Ther. 2015, 39, 204-212. [CrossRef]

65. Sherrington, C.; Tiedemann, A.; Fairhall, N.; Close, J.C.T.; Lord, S.R. Exercise to prevent falls in older adults: An updated meta-analysis and best practice recommendations. NSW Public Health Bull. 2011, 22, 78-83. [CrossRef] [PubMed]

66. Fernandes, V.L.S.; Ribeiro, D.M.; Fernandes, L.C.; Menezes, R.L.d. Postural changes versus balance control and falls in communityliving older adults: A systematic review. Fisioter. Em. Mov. 2018, 31, 15. [CrossRef]

67. Burton, E.; Farrier, K.; Hill, K.D.; Codde, J.; Airey, P.; Hill, A.-M. Effectiveness of peers in delivering programs or motivating older people to increase their participation in physical activity: Systematic review and meta-analysis. J. Sports Sci. 2018, 36, 666-678. [CrossRef] [PubMed]

68. Beauchamp, M.R.; Ruissen, G.R.; Dunlop, W.L.; Estabrooks, P.A.; Harden, S.M.; Wolf, S.A.; Liu, Y.; Schmader, T.; Puterman, E.; Sheel, A.W. Group-based physical activity for older adults (GOAL) randomized controlled trial: Exercise adherence outcomes. Health Psychol. 2018, 37, 451-461. [CrossRef]

69. Hwang, J.; Wang, L.; Siever, J.; Medico, T.D.; Jones, C.A. Loneliness and social isolation among older adults in a community exercise program: A qualitative study. Aging Ment. Health 2019, 23, 736-742. [CrossRef]

70. Zhang, F.; Hausknecht, S.; Schell, R.; Kaufman, D. Can a Wii bowling tournament improve older adults' attitudes towards digital games? In Proceedings of the 8th International Conference of Computer Supported Education CSEDU (2016), Rome, Italy, 21-23 August 2016; SCITEPRESS Science and Technology Publications Ltd.: Setúbal, Portugal, 2016; pp. 211-218.

71. Wu, Z.; Li, J.; Theng, Y.-L. Examining the influencing factors of exercise intention among older adults: A controlled study between exergame and traditional exercise. Cyberpsychology Behav. Soc. Netw. 2015, 18, 521-527. [CrossRef]

72. Pacheco, T.B.F.; de Medeiros, C.S.P.; de Oliveira, V.H.B.; Vieira, E.R.; de Cavalcanti, F.A.C. Effectiveness of exergames for improving mobility and balance in older adults: A systematic review and meta-analysis. Syst. Rev. 2020, 9, 163. [CrossRef]

73. Hill, K.D.; Hunter, S.W.; Batchelor, F.A.; Cavalheri, V.; Burton, E. Individualized home-based exercise programs for older people to reduce falls and improve physical performance: A systematic review and meta-analysis. Maturitas 2015, 82, 72-84. [CrossRef]

74. Larsen, L.H.; Schou, L.; Lund, H.H.; Langberg, H. The physical effect of exergames in healthy elderly-A systematic review. Games Health 2013, 2, 205-212. [CrossRef]

75. Montero-Alía, P.; Miralles-Basseda, R.; López-Jiménez, T.; Muñoz-Ortiz, L.; Jiménez-González, M.; Prat-Rovira, J.; AlbarránSánchez, J.L.; Manresa-Domínguez, J.M.; Andreu-Concha, C.M.; Rodríguez-Pérez, M.C.; et al. Controlled trial of balance training using a video game console in community-dwelling older adults. Age Ageing 2019, 48, 506-512. [CrossRef]

76. Arkkukangas, M.; Sundler, A.J.; Söderlund, A.; Eriksson, S.; Johansson, A.-C. Older persons' experiences of a home-based exercise program with behavioral change support. Physiother. Theory Pract. 2017, 33, 905-913. [CrossRef] [PubMed]

77. Arkkukangas, M.; Söderlund, A.; Eriksson, S.; Johansson, A.-C. Fall preventive exercise with or without behavior change support for community-dwelling older adults: A randomized controlled trial with short-term follow-up. J. Geriatr. Phys. Ther. 2019, 42, 9-17. [CrossRef]

78. Aazh, H. Feasibility of conducting a randomized controlled trial to evaluate the effect of motivational interviewing on hearing-aid use. Int. J. Audiol. 2016, 55, 149-156. [CrossRef] [PubMed]

79. Arkkukangas, M.; Hultgren, S. Implementation of motivational interviewing in a fall prevention exercise program: Experiences from a randomized controlled trial. BMC Res. Notes 2019, 12, 270. [CrossRef]

80. Tanyi, P.L.; Pelser, A. The missing link: Finding space for gerontology content into university curricula in South Africa. Gerontol. Geriatr. Educ. 2019, 40, 491-507. [CrossRef] [PubMed]

81. Bedford, O.; Yeh, K.-H. The history and the future of the psychology of filial piety: Chinese norms to contextualized personality construct. Front. Psychol. 2019, 10, 100. [CrossRef] 
82. Gilbert, P. SA Smartphone Penetration Now at Over 80\%, Says ICASA. Available online: https://www.itweb.co.za/content/Gx wQDM1AYy8M1PVo (accessed on 8 July 2021).

83. McGaughey, R.E.; Zeltmann, S.M.; McMurtrey, M.E. Motivations and obstacles to smartphone use by the elderly: Developing a research framework. Int. J. Electron. Financ. 2013, 7, 177-195. [CrossRef]

84. Czaja, S.J. Usability of technology for older adults: Where are we and where do we need to be. J. Usability Stud. 2019, 14, 61-64.

85. Wollersheim, D.; Merkes, M.; Shields, N.; Liamputtong, P.; Wallis, L.; Reynolds, F.; Koh, L. Physical and psychosocial effects of Wii video game use among older women. Int. J. Emerg. Technol. Soc. 2010, 8, 85-98. 